\title{
Handoff Management in Green FEMTOCELL Network
}

\author{
K.Sethom Ben Reguiga \\ Systel Lab, University of \\ Carthage \\ Tunisia
}

\author{
F. Mhiri \\ Systel Lab, University of \\ Carthage \\ Tunisia
}

\author{
R.Bouallegue \\ Systel Lab, University of \\ Carthage \\ Tunisia
}

\begin{abstract}
Integrated femtocell/macrocell networks, comprising a conventional cellular network overlaid with femtocells, offer an economically appealing way to improve coverage, quality of service, and access network capacity. The key element to successful femtocells/macrocell integration lies in its selforganizing capability. Provisioning of quality of service is the main technical challenge of the femtocell/macrocell integrated networks, while the main administrative challenge is the choice of the proper evolutionary path from the existing macrocellular networks to the integrated network.

In this paper, we propose a new Autonomic Architecture with self organizing capabilities based on the election of a Femtocell cluster Head (FH) for each group of Femtocell APs. The FH will be responsible to dynamically adjust the network overall coverage to save FAP energy and provide better QoS to users. Further it uses an advanced decision algorithm for intelligent handovers.
\end{abstract}

\section{General Terms}

Wireless Networking, Algorithms.

\section{Keywords}

Femtocells, Indoor Wireless Coverage, Self-Organizing

Capability, Handoff, interference.

\section{INTRODUCTION}

Femto-access points (FAPs) are low-power, small-size homeplaced Base Stations (also known as Home NodeB or Home eNodeB) that create islands of increased capacity in addition to the capacity provided by the cellular system. These areas of increased capacity are referred to as femtocells. Femtocells operate in the spectrum licensed for cellular service providers. The key feature of the femtocell technology is that users require no new equipment (UE). Among the benefits of femtocell are low-cost deployment, reduced transmission power, backward compatibility with the macrocellular technology, portability of devices, and scalable deployment. Due to an interest from operators (such as the NGMN (Next Generation Mobile Network) Alliance) and standardization bodies (such as 3GPP, Femto Forum, Broadband Forum, 3GPP2, IEEE $802.16 \mathrm{~m}$, WiMAX Forum, GSMA, ITU-T, and ITU-R WP5D), integrated femtocell/macrocell is expected to be a major part of the IMT-Advanced network architecture [1]. From the wireless operator point of view, the most important advantage of the integrated femtocell/macrocell architecture is the ability to offload a large amount of traffic from the macrocell network to the femtocell network. This will not only reduce the investment capital, the maintenance expenses, and the operational costs, but will also improve the reliability of the cellular networks.

The provision of QoS in femtocellular networks is more difficult than for the existing macrocellular networks due to the large number of neighboring FAPs and the possible interference conditions among the femtocells and between macrocells and femtocells [2]. The QoS of femtocellular networks is influenced by procedures such as resource allocation, interference management, handover control... From among the many QoS issues, we propose hereafter a solution for power and handoff management in femtocell networks based on a distributed and adaptative algorithm between different cluster heads.

\section{THE CLUSTER ARCHITECTURE}

The power and resource allocation in femtocell environment is complex [3]. For that purpose, we propose a new architecture based on the "Femtocell Cluster" concept. Each group of FAPs will form a cluster and a FemtoHead has to be elected. The Head will act as the manager of the cluster.

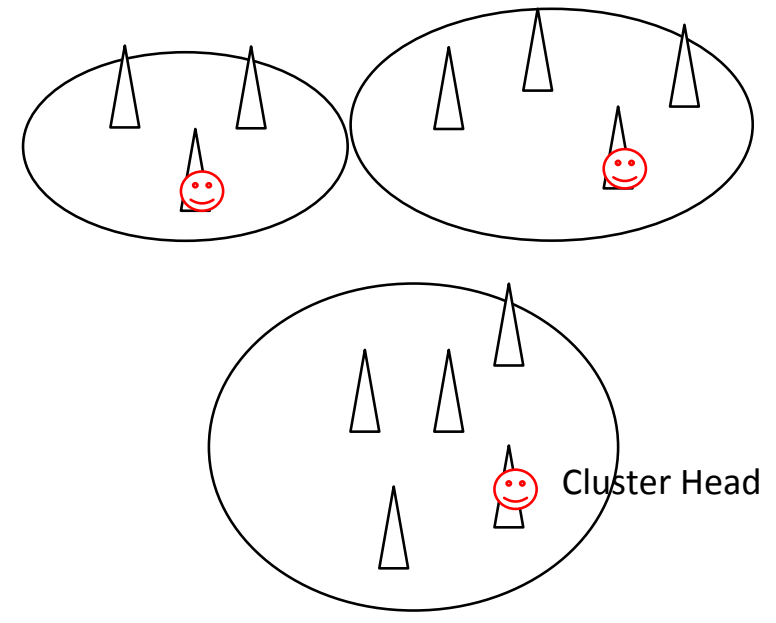

Fig. 1. Femtocell Cluster Architecture

The Femtocell network will be organized in clusters as illustrated in the figure Fig. 1. FAPs communicate together by wired links. Otherwise, in case of outages, wireless transmission is employed. This method has several advantages:

- Traffic in the backbone will be reduced.

- It can also optimize the overall coverage to reduce the power, the resource allocation and the unwanted Handover on floor.

- It can cover a floor area with support for soft handover

Users can access the network according to three priority levels; L1, L2, and L3:

- L1 which is the higher one aims to identify the indoor owner of the Femtocell AP.

- L2 for users belonging to the current Femtocell provider but not connected to their indoor FAP.

- And L3 for any external user. 
The sharing of femtocell resources between these three types of users needs to be finely tuned. We propose that resources go first to the users with higher priority i.e. L1-UE. We reserve for the L1-UE traffic between $50 \%$ and $70 \%$ of the total available Bandwidth. This is to guarantee that the owner of the FAP is not penalized by other L2 or L3 users. The rest of the bandwidth is accorded to the L2 and the L3 users taking into account their priorities of access. $5 \%$ of the traffic is reserved for urgent application.

\subsection{Cluster Head Election Algorithm}

When using clustering, the workload on a cluster head (FH) is larger than for non-cluster heads femtocell-AP. The FHs should therefore be changed periodically in order to distribute the extra workload and energy consumption evenly. First the provider will choose a Femto-Head for every group of FAPs in a way that the distance between the FAPs and the FH is minimized to reduce the cost of transmission energy when wireless communications are required.

The FH will only deserve users with $\mathrm{L} 1$ priority (i.e. the owner of the $\mathrm{FH}$ ) to reduce its workload. Hence its coverage will be reduced to Rmin. The election of a new FH is done periodically (every week) or whenever the current FH is out of work. The new one has to satisfy the following criteria: Having the minimum L2 and L3 users connected to, and using the less bandwidth (less than 60\%).

The Cluster-head FH has several capabilities such as interference and handoff management.

\section{HANDOFF MANAGEMENT}

Handover management is the key aspect in the development of solutions supporting mobility scenarios. It is the process by which Mobile terminal maintains its connection active while moving from one attachment point to another. The handover decision usually involves measurements and information about when and where to perform handover and obtained from one entity or more [4].

We hereafter consider a context-aware handover decision method in a way that multiple criteria from terminal and network sides and advanced decision algorithm is needed. This intelligent system is involved into the handover component of every FAP as shown in figure Fig. 2.

The main three phases of the handover process are:

\subsection{Handover Information Gathering}

Collecting all the contextual information, through monitoring and measurements, require to identify the need for handover and to apply handover decision policies. Here, we regroup these knowledges in two sides:

- Network context: QoS parameters (bandwidth, delay, jitter, packet loss), Traffic load, Monetary cost, Link quality as RSS and BER (Bit Error Rate) of the current access Femtocell and its neighbors (and their relative priorities for the terminal).

- Terminal context: User preferences, Access Mode priority, Service capabilities, Terminal Status (battery), Location and Velocity.

\subsection{Handover Decision}

Determining whether a handover is needed (i.e. Handover Policies Repository and Handover Initiation) and how to perform it by selecting the most suitable Femtocell based on decision parameters. (i.e. Femtocell Selection)

\subsection{Handover Execution}

This means establishing the IP connectivity through the target access femtocell. For that, we can use fast Mobile IP functionalities as an IP mobility management solution.

\section{THE HANDOFF DECISION}

Let's now go in the details of the handover decision module.

\subsection{Handover Policies Repository}

The decision policy rules translate scenarios related to connectivity, network availability, user, or even corporate preferences. The Handover Policies Repository, as described in [5] are a group of rules, defined as follows : "if condition then action" where the action part is triggered when the condition part is satisfied.

Our policy rules, provided for that, are:

- Policy Rule 1:

Condition: User is an L1 and is leaving the coverage.

Action: The Local FAP increases its coverage to maintain the communication, while it has to provide the appropriate Femtocell to which the user can connect to by queering the cluster head. (FH Femtocell-selection)

$$
\text { - Policy Rule 2: }
$$

Condition: User is an L2 and is leaving the coverage.

Action: The cluster Head has to provide the appropriate Femtocell to which the user can connect to. (FH Femtocell Selection)

$$
\text { - Policy Rule 3: }
$$

Condition: User is an L3 and is leaving the coverage.

Action: User searches for a new Femtocell to handoff (terminal Femtocell Selection)

These given policy rules are the basic policies necessary for the proper functioning of the decision process. Some specific policies could be added to the handover policies repository translating special cases.

In case of rule 1 or rule 2 , if a handover is needed (handover initiation factor $=$ YES), a method of decision making by the cluster head is enabled according to pre-configuration steps described in the next section. However, the femtocell selection algorithm described hereafter can also be applied for the last rule i.e in case of mobile assisted handoff (we limit our description hereafter for the two first cases). 


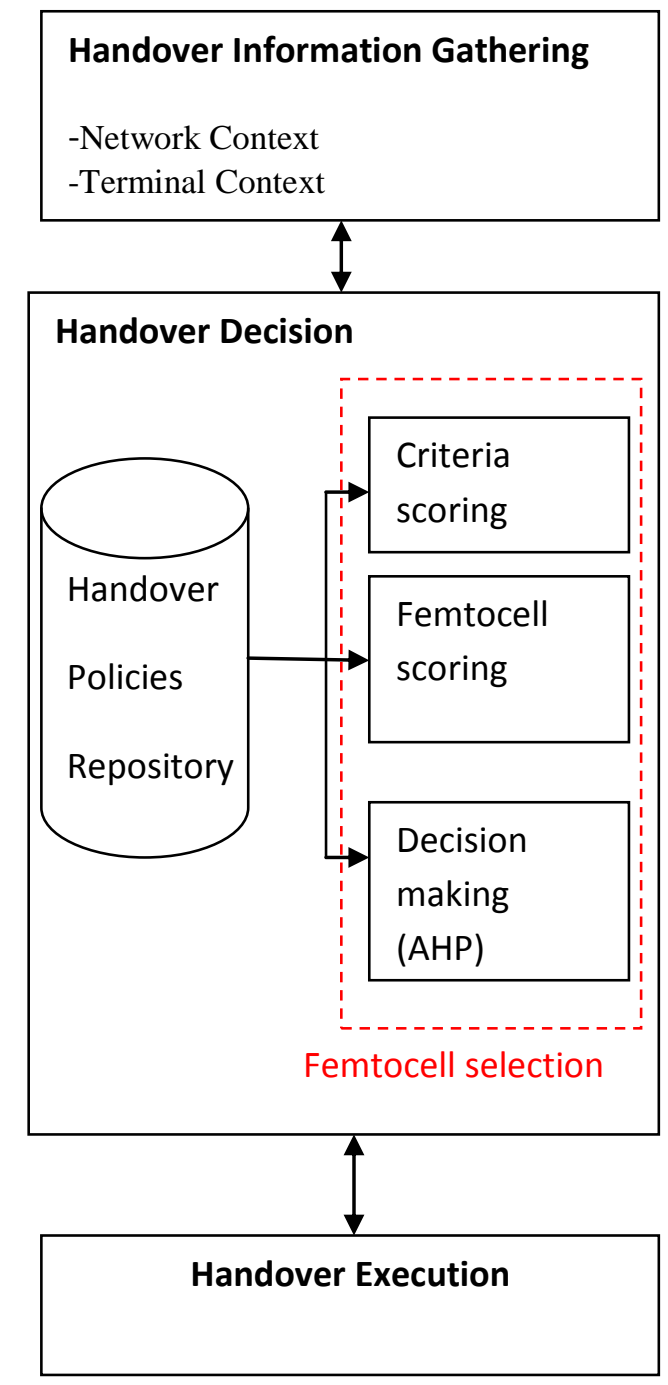

Fig. 2. Handover Component.

\subsection{Femtocell Selection}

At the Femtocell Selection stage, we need more decision criteria from the user side (i.e. user preferences, service capabilities, battery status and Access Mode priority) as well as from the network side (i.e. QoS parameters, cost). The most appropriate Femtocell, from those available, has to be selected satisfying a number of objectives.

So, we consider a multiple objective decision making method in which all available alternatives (Femtocells) are evaluated according to these objectives:

$$
\begin{array}{ll}
\text { - } & \text { Femto-Menbership (L1, L2 or L3), } \\
\text { - } & \text { Low BER, } \\
\text { - } & \text { the Good Battery Status } \\
\text { - } \quad \text { and Maximizing Bandwidth. }
\end{array}
$$

Received signal strength (RSS) will act as a triggering factor, i.e., a new femtocell will be considered as an alternative if and only if the RSS of current femtocell is above threshold at that instant.

Two steps have to be performed: the Criteria Scoring in which the importance of each objective is evaluated according to user preferences, a pre-configuration step, and the Femtocell Scoring in which the available Femtocells are evaluated and compared according to each objective.

\subsubsection{Criteria Scoring:}

A criteria scoring is in charge of mapping priorities given by the user into scores. Based on the priorities given by the user, scores between 1 and 9 are assigned automatically, where 1 is the most preferred one and 9 the least preferred one. The scores are equalspaced integers whose space-gap is defined by:

$$
\mathrm{I}=\left(\mathrm{S}_{\mathrm{h}}-\mathrm{S}_{\mathrm{l}}\right) / \mathrm{Np}
$$

Where $\mathrm{Np}$ is the number of parameters, $\mathrm{S}_{\mathrm{h}}$ and $\mathrm{S}_{1}$ are the highest and the lowest possible scores (i.e. 9 and 1) respectively, and I is the numeric space-gap between two subsequent scores, which is rounded off to the nearest integer.

In our decision process, we consider two categories of services: real-time (voice, video conferencing or streaming, etc.) and non real-time (file transfer, email, web browsing, etc.). The user enters his preferences for both applications. The objectives are: low BER (obj 1), membership (i.e. L1, L2 or L3) (obj2), the good battery status (low power consumption) (obj3), and maximizing bandwidth (obj4). 
Here, $I=\left(S_{h}-S_{1}\right) / N p$ results in $I=2$ while $S_{h}=9, S_{1}=1$ and $N p=$ 4. Obj1, obj2, obj3 and obj4 get scores of $1,3,5$ and 7 respectively (Table 1 ).

Table 1 : Objective scores

\begin{tabular}{c|c}
\hline Voice application & Data application \\
\hline \multicolumn{2}{c}{ Objective scores } \\
\hline 1/Membership 1 & 1/Membership 1 \\
2/BER 3 & 2/bandwidth 3 \\
3/Bandwidth 5 & 3/BER 5 \\
4/ Power 7 & 4/ Power 7 \\
\hline
\end{tabular}

Bandwidth and BER of a particular network indicates its ability to support different types of applications. For example, voice communication needs low bandwidth and low BER but video transmission requires very high bandwidth and can tolerate moderate BER. If QoS is equivalent for two femtocells (i.e membership, BER and bandwidth) then user will always opt for a femtocell which save user battey energy. Thus power is another influencing factor for QoS handover.

\subsubsection{Femtocell Scoring}

We perform real-time calculations for each type of running application. Here, scores have to be assigned to each of the available femtocells based on user preferences. It is simple to get the Femtocell scores related to the Femto-Menbership (L1, L2 or L3). Membership Scores are assigned using the equal-spaced scores between 1 and 9 in a descending order, where the L1 Femtocell has a score of 1, L2 is assigned 4 and L3 gets 7 .

In the case of the obj 1, obj 2 and obj 4, network QoS parameters are very dynamic and each application type has its own QoS requirements. So, we have to express QoS preferences as limits in order to compare them easily with the Femtocell QoS parameters. For that, we use the technique described in [6] to evaluate the QoS Scores of the parameters power, bandwidth and BER. More details are described below (equation 1and 2); where $u i$ and $l i$ are, respectively, upper and lower limits for a particular QoS parameter, and $n i$ is the value offered by a network for that parameter. However, (1) is specific to the bandwidth parameter, where the result is preferred to be as high as possible. Whereas, (2) is specific to power and BER parameters, where the result is preferred to be as low as possible.

Equation (1)

$$
\begin{gathered}
S i=\left(1-\frac{n i-l i}{u i-l i}\right) * 10, \quad l i<n i<u i \\
S i=1, \quad n i \geq u i \\
S i=9, \quad n i \leq l i
\end{gathered}
$$

Equation (2)

$$
\begin{gathered}
S i=\left(\frac{n i-l i}{u i-l i}\right) * 10, \quad \quad l i<n i<u i \\
S i=1, \quad n i \geq u i \\
S i=9, \quad n i \leq l i
\end{gathered}
$$

\subsection{The Decision Making}

It's the final step of the Femtocell selection phase and calculates the final decision when every parameter is already available. The Analytic Hierarchy Process (AHP) [7] is used. A decision maker makes his decisions AHP, developed by Saaty [8].

The steps of AHP are as follows:

1. Calculating the objective priorities or weights from the objective pairwise comparison matrix based on Objective Scores calculated at the step1.

$$
A=\left(\begin{array}{ccc}
1 & \cdots & R S 1 n \\
\vdots & \ddots & \vdots \\
1 & \cdots & 1
\end{array}\right)
$$

Where:

$$
\begin{array}{ll}
\frac{1}{R S i j}=\left(1-\frac{S i}{S j}\right) * 10, & S i>S j \\
R S i j=\left(1-\frac{S j}{S i}\right) * 10, & S i<S j
\end{array}
$$

Then, we develop a normalized matrix $\left(\boldsymbol{A}^{\prime}\right)$ by dividing each element in a column of the pair-wise comparison matrix $\boldsymbol{A}$ by its column sum. The sum of every column of a correctly normalized matrix will always be 1 . Then we obtain the priority vector $\mathrm{P}$ related to objectives.

$$
\begin{gathered}
a^{\prime} i j=\frac{a i j}{\sum_{k=1}^{n} a k j} \\
\text { And } \\
p k=\sum_{j} a^{\prime} k j
\end{gathered}
$$

2. In this stage, we have to calculate the Femtocells weights with respect to each objective through a Femtocells pairwise comparison matrix.

$$
\text { Fem1 Fem } 2
$$

$$
\left(\begin{array}{cc}
1 & R S 12 \\
\frac{1}{R S 12} & 1
\end{array}\right)
$$

3. Finally, we determine the sum of products of objective weights and Femtocell weights for each Femtocell according to these last steps and select the Femtocell with the highest sum (3).

$$
\text { Score Network } i=\sum_{1}^{i j} \text { Wnij woj }
$$




\section{EXPEREIMENTAL RESULTS}

A mobile user UE1 is moving inside the enterprise environment (figure 3). First it's connected to his femtocell L1. After a while he has a meeting staff during 1 hour in another room covered by an L2 femtocell so he moves to point A. Finally at 5pm, he is living the enterprise through point $\mathrm{B}$.

\section{Working office}

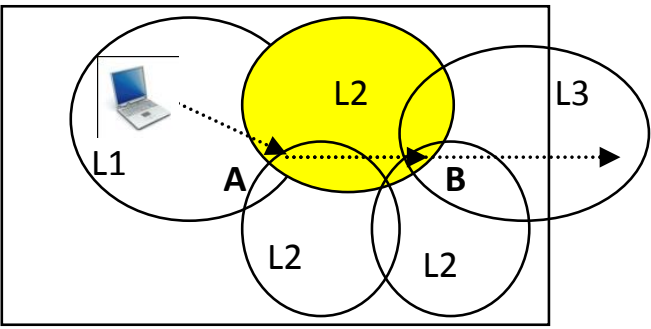

Table 2: Networks characteristics

\begin{tabular}{|c|c|c|}
\hline & Fem1 & Fem2 \\
\hline \multicolumn{3}{|c|}{ Position A } \\
\hline Membership & L2 & $\mathrm{L} 2$ \\
\hline $\mathrm{Bd}$ & $10 \mathrm{Mb} / \mathrm{s}$ & $20 \mathrm{Mb} / \mathrm{s}$ \\
\hline $\mathrm{Pw}$ & $10 \mathrm{~mW}$ & $10 \mathrm{~mW}$ \\
\hline BER & 4 & 3 \\
\hline \multicolumn{3}{|c|}{ Position B } \\
\hline Membership & L2 & L3 \\
\hline $\mathrm{Bd}$ & $15 \mathrm{Mb} / \mathrm{s}$ & $10 \mathrm{Mb} / \mathrm{s}$ \\
\hline $\mathrm{Pw}$ & $15 \mathrm{~mW}$ & $10 \mathrm{~mW}$ \\
\hline BER & 4 & 2 \\
\hline
\end{tabular}

Fig.3. Network availability at different positions

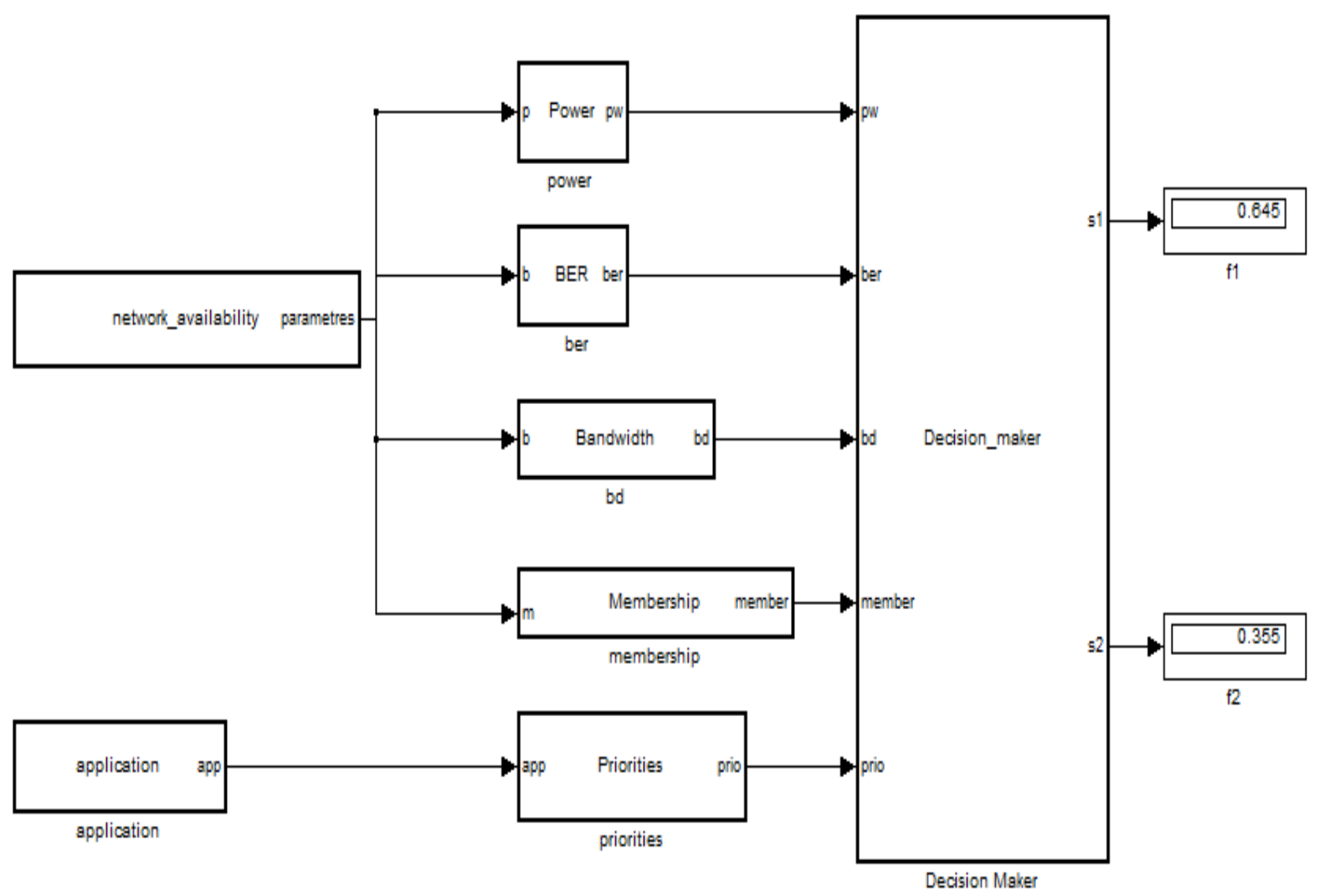

Fig.4 : Simulink testbed

Figure 4 shows the SIMULINK model [9] developed for network selection in femtocell networks. Network availability block scans all available frequencies to detect all available femtocells on the surrounding of the mobile user. This process is based on the power of the received signal strength [10].after the end of this step, the system do not select the most powerful signal as it is done in traditional handover, other criteria are needed to make the decision. Outputs of this block trigger the other bloc.
The power, BER, bandwidth and Membership blocks calculate the scores of each criteria according to the current mobile user context. Finally, a display shows the final ranking of the different active femtocells. Network with highest ranking is the selected network.

The simulation results shown here are analyzed for both categories of traffic voice and data. 
We suppose that the femtocells have wimax antenna (max Bandwdth $30 \mathrm{Mb} / \mathrm{s}$, max power 15 and max BER is 5). The characteristics of traversed femtocells are shown is Table 2. Using equation 1 and 2, the AHP_application, BER_AHP, PW_AHP and femto_priority blocks calculate the relative scores of each objective at the point A and B. The outputs are shown in Table 3 and Table 4.

\section{At point A Table 3: objectives scores at point A}

\begin{tabular}{|c|c|}
\hline VOICE APPLICATION & DATA APPLICATION \\
\hline \multicolumn{2}{|c|}{ BER scores } \\
\hline $1 /$ fem 26 & $1 /$ fem 26 \\
\hline $2 /$ fem 18 & $2 /$ fem 18 \\
\hline \multicolumn{2}{|c|}{ Membership scores } \\
\hline $1 /$ fem 24 & $1 /$ fem 24 \\
\hline $2 /$ fem 14 & $2 /$ fem 14 \\
\hline \multicolumn{2}{|c|}{ Power scores } \\
\hline $1 /$ fem 17 & $1 /$ fem 17 \\
\hline $2 /$ fem 27 & $2 /$ fem 27 \\
\hline \multicolumn{2}{|c|}{ Bandwidth } \\
\hline $1 /$ fem 26 & $1 /$ fem 26 \\
\hline $2 /$ fem 18 & 2/fem 18 \\
\hline
\end{tabular}

At point B:

Table 4: objectives scores at point B

\begin{tabular}{|c|c|}
\hline VOICE APPLICATION & DATA APPLICATION \\
\hline \multicolumn{2}{|c|}{ BER scores } \\
\hline $1 /$ fem 24 & $1 /$ fem 24 \\
\hline $2 /$ fem 18 & $2 /$ fem 18 \\
\hline \multicolumn{2}{|c|}{ Membership scores } \\
\hline $1 /$ fem1 4 & $1 /$ fem 14 \\
\hline $2 /$ fem 27 & $2 /$ fem 27 \\
\hline \multicolumn{2}{|c|}{ Power scores } \\
\hline $1 /$ fem 27 & $1 /$ fem 27 \\
\hline $2 /$ fem 19 & $2 /$ fem 19 \\
\hline \multicolumn{2}{|c|}{ Bandwidth } \\
\hline $1 /$ fem 22 & $1 /$ fem 22 \\
\hline $2 /$ fem 12 & $2 /$ fem 12 \\
\hline
\end{tabular}

The decision Maker block first calculate the normalized matrix for objective pairwise- Table 6 . Then it generates the network matrix for voice application- Table 5. The network pairwise comparison matrix for data application is similar to voice application one.

Here, we can have the values for the BER objective at point $\mathrm{B}$ for example, wnfem1,BER $=0.166$ and wnfem2,BER $=0.833$ for voice application.

Finally the matlab model generate the scores for each candidate femtocells according to (3) at point B :

- $\quad$ Scorefem $1=0.360$, Scorefem $2=1.196$ for voice application

- $\quad$ And Scorefem $1=0.375$, Scorefem $2=0.464$ for data application.
The network with the highest score, FEM2 i.e the L3, is finally selected for voice application and for data application.

The same steps were applied for the handoff decision in point $\mathrm{A}$ and results in the selection of fem 2 for data and voice.

Table 5: normalized network matrix at point $B$

\begin{tabular}{l|l|l}
\hline \multicolumn{3}{c}{$\begin{array}{c}\text { Network pairwise comparison matrix } \\
\text { Normalized matrix (voice) }\end{array}$} \\
\hline BER & FEM1 & FEM2 \\
\hline FEM1 & 0.166 & 0.166 \\
FEM2 & 0.833 & 0.833 \\
\hline POWER & FEM1 & FEM2 \\
\hline FEM1 & 0.31 & 0.31 \\
FEM2 & 0.689 & 0.689 \\
\hline BANDWIDTH & FEM1 & FEM2 \\
\hline FEM1 & 0.5 & 0.5 \\
FEM2 & 0.5 & 0.5 \\
\hline MEMBERSHIP & FEM1 & FEM2 \\
\hline FEM1 & 0.19 & 0.19 \\
FEM2 & 0.8067 & 0.8067 \\
\hline
\end{tabular}

Table 6: objectives matrix at point $B$

Objective pairwise comparison matrix

Normalized matrix

\begin{tabular}{|c|c|c|c|c|c|}
\hline VOICE & Power & BER & $\begin{array}{c}\text { Bandw } \\
\text { idth }\end{array}$ & $\begin{array}{c}\text { Member } \\
\text { ship }\end{array}$ & $\begin{array}{c}\text { Prior } \\
\text { ity }\end{array}$ \\
\hline Power & 0.108 & 0.0213 & 0.0411 & 0.0739 & $\begin{array}{c}0.06 \\
11\end{array}$ \\
\hline BER & 0.324 & 0.5675 & 0.329 & 0.5916 & $\begin{array}{c}0.45 \\
3\end{array}$ \\
\hline Bdth & 0.162 & 0.1419 & 0.0822 & 0.493 & $\begin{array}{c}0.21 \\
98\end{array}$ \\
\hline M-ship & 0.925 & 0.810 & 0.939 & 0.6337 & 0.82 \\
\hline \multicolumn{6}{|c|}{ Normalized matrix } \\
\hline DATA & $\begin{array}{c}\text { POW } \\
\text { ER }\end{array}$ & $\begin{array}{c}\text { MEMBER } \\
\text { SHIP }\end{array}$ & BER & BD & $\begin{array}{c}\text { Prior } \\
\text { ity }\end{array}$ \\
\hline POWER & $\begin{array}{c}0.093 \\
2\end{array}$ & 0.1138 & 0.0389 & 0.0259 & $\begin{array}{c}0.06 \\
79\end{array}$ \\
\hline $\begin{array}{l}\text { MEMBER } \\
\text { SHIP }\end{array}$ & $\begin{array}{c}0.798 \\
2\end{array}$ & 0.9751 & 0.8882 & 0.9879 & $\begin{array}{c}0.91 \\
23\end{array}$ \\
\hline BER & $\begin{array}{c}0.266 \\
1\end{array}$ & 0.1219 & 0.1110 & 0.037 & $\begin{array}{c}0.13 \\
40\end{array}$ \\
\hline $\mathrm{BD}$ & $\begin{array}{c}0.532 \\
3\end{array}$ & 0.1463 & 0.4441 & 0.1482 & $\begin{array}{c}0.31 \\
77\end{array}$ \\
\hline
\end{tabular}

With regard to hand off execution performance, there is a need for developing algorithms for connection management and optimal resource allocation for seamless mobility. The Media Independent Handover (MIH) architecture [11] is used for the special case of handoff optimization between heterogeneous networks. The signaling messages are exchanged by triggers in 802.21 is obtained through Service Access Points (SAP). These messages must be delivered in a timely and reliable manner. 


\section{CONCLUSION}

Integration of femto-cellular networks with macrocellular networks, as well as with other non-wireless networks, is essential for the successful deployment of the femtocell technology. Our discussions in this paper on femtocells focus on the effects of the mass deployment on the handoff issue. A simple and effective method has been proposed to perform efficient and intelligent handover management for femtocell systems. Simulation results throw Matlab simulink proof the viability of the proposed method.

\section{REFERENCES}

[1] L. Eastwood, S. Migaldi, Q. Xie, and V. Gupta, "Mobility Using IEEE 802.21 in a Heterogeneous IEEE 802.16/802.11-based, IMT-Advanced (4G) Network," IEEE Wireless Commun., April 2008.

[2] D. Lopez-Perez; Valcarce, A.; G. de la Roche, Jie Zhang, «OFDMA femtocells: A roadmap on interference avoidance », IEEE communication magazine, pp 41-48, issue 9, Sept 2009.

[3] S. Kishore, L.J. Greenstein, H.V. Poor, and S.C. Schwartz, "Uplink User Capacity in a Multicell CDMA System with Hotspot Microcells," IEEE Trans. On Wireless Communications, vol. 5, no. 6, pp. 1333 1342, June 2006.

[4] Jung-Min Moon; Dong-Ho Cho, "Efficient handoff algorithm for inbound mobility in hierarchical macro/femto cell networks",IEEE communications letters, pp 755-757, Vol.13, Oct 2009.
[5] H. Wang, R. Katz, and J. Giese, "Policy-enabled handoffs across heterogeneous wireless networks," in Workshop on Mobile Computing Systems and Applications (WMCSA '99), pp. 51-60, New Orleans, La, USA,February 1999.

[6] T. Ahmed, K. Kyamakya, and M. Ludwig, "A contextaware vertical handover decision algorithm for multimode mobile terminals and its performance," in IEEE/ACM EATIS '06, pp. 19-28.

[7] T. Saaty. How to Make a Decision: The Analytic Hierarchy Process. European Journal of Operational Research, 48(1):9-26, 1990.

[8] R. Y. Kim, J. S. Kwak, and K. Etemad, "WiMAX femtocell: Requirements, challenges, and solutions," IEEE Commun. Mag., vol. 47, no. 9, pp. 84 - 91, September 2009.

[9] Simulink, www.mathworks.fr

[10] D. Griffith, R. Rouil, N. Golmie, "Performance metrics for IEEE802.21 Media Independent Handover (MIH) signaling" Springer, Wireless Personal Communications, 2008.

[11] L. Cordeiro, M. Curado, P. Neves, S. Sargento, G. Landi, $\mathrm{X}$. Fu, "Media Independent Handover Signalling layer protocol (MIH NSLP)", in: IETF draft, 2008. 